\title{
EL ABASTECIMIENTO DE MÉXICO, 1761-1786: SEMEJANZAS Y DIFERENCIAS ENTRE LA NUEVA ESPAÑA Y LA ESPAÑA EUROPEA
}

\author{
POR
}

\author{
JOSÉ ANDRÉS-GALLEGO
}

Centro de Estudios Históricos (CSIC)

\begin{abstract}
En el periodo estudiado (1761-1786) fueron bastantes los motines de abastecimiento (foof riots) habidos en la España europea y pocos los registrados en Nueva España. El autor intenta buscar una explicación examinando el sistema de abastecimiento mexicano en una perspectiva económica, social y antropológica, y comparándolo con el español. La comparación pone de manifiesto diferencias sociales (abasto indígena al margen de los cauces públicos en gran parte), doctrinales (doctrinas comunitarias sobre la propiedad) y mentales (mayor peso de la limosna y cultura de la protesta menos desarrollada).
\end{abstract}

En las Quince revoluciones y algunas cosas más trazábamos una tipología de las protestas populares de 1762-1767 en España y las Indias españolas y una de las cosas que señalábamos es que en América, en esos años, no hubo motines provocados por la carestía, la escasez o el hambre, a diferencia de la península europea, donde los más de los tumultos de aquellos días tuvieron tal naturaleza ${ }^{1}$. Nos preguntábamos por qué y aventurábamos una hipótesis que ahora, al concluir la segunda entrega de Actitudes ante el poder en el mundo hispano ${ }^{2}$, estamos en condiciones de verificar o de corregir. Decíamos que la exigencia de un abasto barato y suficiente sólo era verosímil en una comunidad distanciada ya del autoabastecimiento y

\footnotetext{
Sigla utilizada:

AHCM. Archivo Histórico de la Ciudad de México.

1 Quince revoluciones y algunas cosas más, Madrid, Ed. Mapfre, 1992, pág. 211-5.

2 Con un segundo libro que se titulará probablemente Esquilache y el pan.
} 
dotada de un sistema de intercambios más o menos fluido y ambicioso pero en todo caso supramunicipal. Y nos preguntábamos si sucedía que, en América, el abastecimiento no dependía de un mercado como éste porque era mayor - suficientemente mayor - el nivel de autoabastecimiento, y esto, por la pura y simple riqueza de los unos, por la frecuencia del pago de los salarios en especie o incluso por una mayor sobriedad. Adujimos allí algunos ejemplos que nos llevaban a pensar que ocurría en efecto así. Ahora nos propondríamos en cambio responder a la misma duda en sentido contrario: no desde el punto de vista de la posible originalidad de América, sino desde el de la posible semejanza con España. Dicho de otra manera: ¿en qué se diferenciaba el sistema de abastecimiento de una y otra ribera del Atlántico? Y, si no se diferenciaba, ¿por qué en uno había más protestas que en el otro?

Como América es grande y el asunto requiere una microhistoria, centraremos nuestra comparación en uno de los lugares que, por su envergadura demográfica, podía resultar más conflictivo: México.

\section{El ABASTECIMIENTO DE MÉXICO: EL PÓSITO Y LA ALHÓNDIGA ${ }^{3}$}

El abastecimiento de la ciudad de México, como el de la ciudad de Madrid o el de la de Cádiz, dependía del clima; una grave seca, como allí se decía, o una helada a destiempo podían alterar el ciclo vegetal y dar lugar por tanto a una peor cosecha $\mathrm{y}$, con ello, a una situación de escasez o de carestía. Acababa de suceder en 17611762, como ocurriría en España en 1765-1766: la falta de lluvias, no sólo en la ciudad y su comarca sino tierra adentro, hacían temer ya al mediar junio de 1761 que hubiera escasez de semillas, principalmente de maíz, que era el alimento básico, y también mortandad de ganado si faltaban con ello los pastos, y con todo esto enfermedades. Además, la poca agua caída lo había hecho a mochones y, con el granizo consiguiente, se había perdido el trigo en no pocas haciendas ${ }^{4}$.

\footnotetext{
3 Sobre estas instituciones que regulaban en la ciudad de México el abasto, DIEGo LÓPEZ RosADo (1988), El abasto de productos alimenticios en la ciudad de México. México, FCE, 86-8, 113-7. Sobre lo mismo en toda Nueva España, VÁzQUEZ (1968).

4 Cfr. Irene VÁZQUEZ DE WARMAN, «El pósito y la alhóndiga en la Nueva España». Historia Mexicana, México, 1968, pp. 395-426. AHCM, vol. 82A, Actas de Cabildo, f. 57v, 17 de junio de 1761. En el mismo sentido, ibidem, vol. 751A, Juntas de la Ciudad, f. 93v, 3
}

R. I., 1997, n. $^{\circ} 209$ 
Lo mismo volvería a pasar, más gravemente, en 1785 y 1786, en que la seca afectaría a una gran parte del enorme reino de Nueva España. En el primero de estos años, en pleno mes de agosto de 1785, a la falta de agua se habían de sumar unas insólitas heladas que, además de hacer daño a las plantas, se lo hicieron a las personas y sembraron la ciudad de México de una fiebre catarral epidémica, benigna en sí, pero gravísima para los organismos debilitados por el hambre ${ }^{5}$.

Igual que en todas partes, hacer frente a estos eventos era una de las primeras obligaciones del cabildo de la corte novohispana; «el vínculo de su obligación - decía de sí mismo en 1762 el procurador general de la ciudad, que era a la vez regidor, don Gaspar Hurtado de Mendoza- es atender a el público en que tenga suficiente provisión de víveres, y a acomodados precios que se pueda» ${ }^{6}$. El cabildo de México estaba formado -en 1761-1762- por media docena de regidores perpetuos, que se reunían con cierta regularidad en dos cámaras. Una era el propio cabildo y la otra las Juntas de Ciudad, en las que los miembros de aquél - los regidores, con el corregidor a la cabe$\mathrm{za}$ - trataban con el juez superintendente conservador de propios y rentas los negocios que requerían una decisión económica. Las Juntas de Ciudad eran, por tanto, una suerte de cabildo paralelo que aseguraba la viabilidad de los acuerdos adoptados y señalaba los medios concretos que había que poner para hacerlos efectivos.

\footnotetext{
de septiembre. La de 1761-1762 fue sin embargo una escasez relativa: no la hubo grave desde la de 1742 y hasta la de 1771. En este sentido, Enrique FloRESCANO, Precios del maíz y crisis agrícolas en México (1708-1810): Ensayo sobre el movimiento de los precios y sus consecuencias económicas y sociales. México. El Colegio de México, 1969, p. 89. De todos modos, la investigación pionera de Florescano sobre los precios del maíz y las crisis agrícolas debe completarse con las investigaciones que han seguido y que sirven para elaborar una nueva serie a Richard L. GARNER, «Prices and Wages in Eighteen Century Mexico», en Lyman L. JOHNSON y Enrique TANDETER, Essays on the price History of Eighteen Century Latin America, Albuquerque, 1990, pp. 78-81 y 83. Según ella, la mayor inflación precedente (síntoma probable de escasez) se había dado en 1750; los años cincuenta fueron años de precios moderados, hasta 1760-1762, en que se registró una cierta inflación, para bajar de nuevo, incluso por debajo de la cota media de los años cincuenta, en 1763-1769, años de verdadero auge cerealístico, según indicaba ya Florescano, loc. cit., 112-39 y 159-62.

5 Vid. Informe de la Audiencia, 19 de mayo de 1786, АнСм, vol. 3.674, Policia: Salubridad, exp. 4 (Junio de $1787=$ Año de $1786=$ Expediente formado sobre la curación de la presente epidemia...), f. 19v.

6 AнCM, vol. 83A, Actas de Cabildo, f. 25, 23 de agosto de 1762.
} 
Como en tantos otros lugares, al comenzar cada año los del cabildo se reunían para proveer un sinfín de cargos, entre los cuales se encontraban los de diputados del pósito y la alhóndiga. Quienes a su vez se reunían en Juntas del Pósito, para el gobierno de estas instituciones, como se hacía en tantas poblaciones de España. En México, los diputados en cuestión eran regidores; no así el alcaide de la alhóndiga y mayordomo de los maíces del pósito, cargo que solía recaer en persona ajena al cabildo y que se encargaba del gobierno diario de ambas instituciones y de llevar sus cuentas a cambio de cobrar un salario importante, en términos relativos. El alcaide debía vigilar lo que entraba y salía en uno y otro centros, incluso en días festivos, y si había que vaciar los costales, asolearlo o dejarlo encostalado, en tanto que en la Junta del Pósito se tomaban las providencias pertinentes para la dirección mejor del mismo, se ordenaba la compra de maíz, o la venta y, cuando procedía, se fijaban los precios ${ }^{7}$.

El pósito y la alhóndiga funcionaban de forma parecida al de tantos otros de España y la propia América, dentro de la variedad de maneras que había entre ellos. En 1761-1762 el pósito de México servía solamente para asegurar el abastecimiento de maíz; no hacía la función de prestar semilla que hemos visto en otros lugares. Cuando lo creían prudente, los de la Junta del Pósito enviaban comisionados a comprar grano o lo adquirían en la alhóndiga del que traían o enviaban a ella los cosecheros 8 . El caso era que las trojes de aquél estuvieran llenas para servir si hacía falta. Mientras no sucediera así, había que cuidar de que el maíz entrojado en el pósito no se escalentara y picara (que eran los verbos que expresaban el peligro habitual). Cuando surgía este peligro, el alcaide tenía que mandarlo a la alhóndiga para que se pusiera a la venta y rellenar las trojes del pósito, por lo general con maíz de aquélla9 ${ }^{9}$.

7 Sobre los deberes del alcaide, АHCM, vol. 3.694 (Pósito y Alhóndiga, 1693 a 1770), exp. 51 (Autos del Alcaide de Alhóndiga...).

8 Vid. por ejemplo ibidem, exp. $57(1771=$ Autos sobre providencia para compra de Maízes en tierra fría, para el Pócito de esta Nobilísima Ciudad).

9 Vid. por ejemplo АнCM, vol. 751A, Juntas de Ciudad, f. 94, 10 de septiembre de 1761. También ibidem, vol. 2.189 (Cuentas del Pósito. 1738 a 1812), exp. $9(1760=$ Autos sobre venta de maíces...), y vol. 3.694 (Pósito y Alhóndiga. 1693 a 1770), exp. 51 (Autos del Alcaide de Alhóndiga, y Mayordomo de los maíces del Pócito sobre que se vacíen los troges de ella). A lo mismo se debe referir la petición del coronel don Manuel Ribas Cacho de que no se reemplazara el trigo del pósito porque se había echado a perder: vid. ibidem, vol. 82A, Actas de Cabildo, f. 62v, 17 de agosto de 1761. Probablemente se quería decir

R. I., $1997, \mathrm{n}^{\circ} 209$ 
La alhóndiga, por tanto, se abastecía con el trigo del pósito y con el que enviaban los cosecheros o llevaban los trajineros directamente a ella, para su venta al público (exactamente igual, por lo demás, que se hacía por ejemplo en Sevilla ${ }^{10}$ ). Como aquí, todo el maíz que entrara en México -excepto el destinado al pósito y el de la catedral tenía que pasar por la alhóndiga y ser vendido en ella. A nadie estaba permitido vender directamente a particulares, ni siquiera a los panaderos, como se pudo hacer en la España europea desde la liberación del comercio de granos de 1765. En México, también los panaderos tenían que ir allí a llevar a cabo las compras. Lo cual permitía a las autoridades, por medio del alcaide, controlar la calidad de lo que se vendía y cobrar además un pequeño sobreprecio por cada fanega. Exactamente igual que en Sevilla o Madrid salvo en lo dicho: el pósito y la catedral, que tenía su propio lugar - la colecturía - donde almacenaba y vendía el grano de sus rentas ${ }^{11}$.

La alhóndiga tenía que estar dotada por tanto de trojes suficientemente espaciosas; la de México tenía dos pisos pero no estaba bien cuidada y, en una circunstancia como la de 1762, hubo particulares que tuvieron que entrojar su maíz en las del pósito, con el consiguiente problema para el almacenamiento del maíz que se compraba para éste ${ }^{12}$.

Igual que en todas partes, el control de la calidad le correspondía en primer lugar al alcaide pero era en último término responsabilidad del corregidor $\mathrm{y}$, en la práctica, la vigilaban todos, desde el virrey a los encomenderos (que eran aquéllos a quienes los hacendados con-

que, al estar perdido, no se podía reemplazar por maíz de la alhóndiga, llevando a ella el que había en el pósito, sino que había que destruirlo o dárselo a los animales.

10 Lo estudiamos en «La búsqueda de la justicia en Andalucía: dieciocho siglos olvidados», en La doctrina social de la Iglesia: En el I Centenario de la Encíclica «Rerum Novarum», Jaén, Seminario Diocesano, 1993, pp. 83-136.

11 Vid. AHCM, vol. 82A, Actas de Cabildo, f. 63, 3 de septiembre de 1761.

12 Vid. decreto del virrey ordenando desocupar la troj de la Manga, del Pósito, y cualquier otra que se hallase ocupada por maíces particulares, AHCM, vol. 83A, Actas de Cabildo, f. 13, 5 de marzo de 1762. Sobre la situación del edificio en 1762, ibidem, vol. 3.694 (Pósito y Alhóndiga. 1693 a 1770), exp. 48 (Avisa el Maestro Mayor de Ciudad el mal estado y ruina que amenaza la Alhóndiga). También, ibidem, exp. 54 (Acuerdo de la Junta de la Ciudad a consecuencia de la proposición del Señor Procurador general sobre que se dividan las tres trojes de arriba con puertas separadas para usar de ellas como convenga y poder dar lo sobrante a los Labradores por que sin ellas no pueden tener Maíces ni hacer en la Alhóndiga el repuesto conveniente). 
fiaban la venta de sus maíces en la corte ${ }^{13}$ ). En 1764, un oidor de la Audiencia actuaba como comisionado del virrey marqués de Cruillas para el arreglo de los panaderos de la corte y celaba precisamente por la calidad del grano ${ }^{14}$, en tanto que, al año siguiente, sería un cosechero quien denunciara a otro por vender en la alhóndiga maíz en malas condiciones ${ }^{15}$. Denuncias como ésta es natural que se dieran porque, tal como estaban las cosas en 1761-1762, el maíz apto para el consumo humano se vendía al público por riguroso turno de entrada en la alhóndiga, salvo el del pósito, al que se daba preferencia dos días por semana señalados por el cabildo si es que hacía falta venderlo por una razón $u$ otra. A un propietario o encomendero le interesaba por lo tanto adelantar puestos y no dejaba de intentarlo si veía que el maíz de algún propietario que le precedía en el turno no tenía la calidad exigida.

Cuando era grande el volumen del grano malogrado en la alhóndiga $o$ en el pósito, las autoridades municipales podían llegar a imponer a los dueños de las tocinerías que lo compraran a prorrata, claro está que a un precio menor que el del bueno' ${ }^{16}$.

Los del cabildo no se ocupaban sólo del maíz; debían prestar atención a todo género de abasto, igual que en España, fuera papel, cacao, canela o hierro, por citar los que preocupaban al procurador general de México en 1762. En Guatemala y en Campeehe y otras provincias - aducía por ejemplo- se envolvía el tabaco en hojas de maíz, que era mejor y más barato; así que había que informarse de la opinión correspondiente del protomedicato por si se consideraba oportuno disponer lo propio en las cigarrerías mejicanas y conseguir con eso el consiguiente ahorro ${ }^{17}$.

Pero había algunos productos, como el propio maíz, que administraban los del cabildo por sí mismos, como corporación. No así el

13 Vid. por ejemplo Ансм, vol. 82A, Actas de Cabildo, f. 75, 4 de diciembre de 1761, y vol. 2.189 (Cuentas del Pósito. 1738 a 1812), exp. 9 (1760 = Autos sobre venta...).

14 Vid. AHCM, vol. 3.452 (Panaderías y pulperías), exp. 4 (México Año de $1764=$ Causa formada Contra Don Diego Retana...).

15 Cfr. AнCM, vol. 3.694 (Pósito y Alhóndiga. 1693 a 1770), exp. 52 (D. Juan de Castañiza sobre que se tome información de la calidad y circunstancia del maís que está vendiendo en la Alhóndiga al precio de doce reales $D$. Cristóbal Fernández).

16 Vid. por ejemplo AHCM, vol. 2.189 (Cuentas del Pósito. 1738 a 1812), exp. 11 (1768 = Autos de venta de maízes...).

17 Vid. AHCM, vol. 83A, Actas de Cabildo, f. 25, 23 de agosto de 1762. Insiste en ello el 23 de septiembre, añadiendo el afrán (¿por azafrán?): ibidem, f. 28. 
trigo - que era el principal abasto en España- por más que éste se consumiera en crecida cantidad también en la corte novohispana. De lo que se trataba especialmente era de asegurar el alimento de los más pobres y, como aún hemos de ver al hablar de la dieta, éstos consumían ante todo maíz. El trigo, lo enviaban los cosecheros directamente a los molinos y aquí iban a comprarlo los panaderos ${ }^{18}$.

Como en la otra ribera del Atlántico, unos de esos abastos los llevaba el cabildo por administración (caso del maíz mismo por medio del pósito) y otros los arrendaba, como ocurría con el siguiente en importancia, que era la carne.

Tal como se fijó el procedimiento en 1777, recogiendo experiencias de años y siglos anteriores, el abasto de la carne se remataba de manera que pudiera comenzar en Pascua de Resurrección y terminar el Sábado de Gloria dos años después ${ }^{19}$. Para ello -e igual que en las ciudades españolas de cierta envergadura - no se anunciaba sólo en México, sino además en Puebla, Guadalajara, Valladolid y Querétaro. Y es que encargarse del abasto en cuestión exigía tener bastante dinero y requería mover ganados por un extenso territorio; no bastaban los de la comarca de México, con ser como eran abundantes. Sobre todo en la seca, era importante que pudieran contar con los toros que subían de la costa de Guadalajara a Guapanga. Lo cual quería decir que el abastecedor de la carne tenía que ocuparse incluso de arreglar los caminos por donde transitaban, dado el volumen y por lo tanto el mal que hacían.

Luego, una vez en la ciudad, necesitaban pastos abundantes para esperar la hora de la muerte. Así que se ponían a su disposición los ejidos lindantes con las calzadas (o sea los ríos o canales) de La Piedad, Chapultepec y San Antonio Abad y se les daba prioridad en el arrendamiento de las ciénagas (allí, siénegas) de Xochimilco, Misquic, Tlaguac y Lerma, en que tenía dominio la Ciudad.

\footnotetext{
18 Vid. por ejemplo Ансм, vol. 3.452 (Panaderías y pulperías), exp. 3 (Bando sobre manifestaciones y remesas de trigos).

19 Era en efecto por dos años. Esto y todo lo que sigue, mientras no se diga otra cosa, en AHCM, vol. 3.779 (Real Audiencia. Fiel ejecutoria. Abastos), exp. $1779=$ Copia del remate de abasto de carnes de esta Corte... En vista de la diversidad de condiciones que ponían los rematantes, en 1777 se optó por fijarlas, recogiendo la experiencia de siglos y algunas medidas concretas que habían adoptado en años anteriores el marqués de Croix y el visitador Gálvez.
} 
Había matadero municipal, que se arrendaba al abastecedor para que sacrificara las reses. Para que la carne llegara al nacer el sol a las tablas y no estuviera aún fresca, la matanza debía comenzar a las tres de la mañana y la res muerta debía estar colgada mientras la desollaban.

Los lugares donde expender la carne eran fijos: había concretamente siete tablas en la carnicería mayor y otras siete distribuidas por los barrios de México. En todas ellas tenía el obligado (o sea aquel que ganaba en la subasta y se obligaba a servir la especie en cuestión) que abastecer de sol a sol de carnero y de toro, matando todos los animales necesarios. Y, aparte, debía sacar carnero a la venta en otras cuatro tablas que llamaban despensas de Palacio, San Pedro y San Pablo, San Hipólito y San Juan de Letrán.

Se obligaba también a abastecer los pueblos y lugares agregados a la ciudad, que eran Guadalupe, La Piedad, Mexicalcingo, Xochimilco, Istapalapa, Chalco, Tlalmanalco, Tlayacapam y Lerma ${ }^{20}$. Quedaba en cambio a su arbitrio vender o no carnero en el rastro de San Antonio Abad, como venía haciéndose desde 1616, así como servir ternera, cuyo consumo se estaba difundiendo mediado el siglo XVIII. Si optaba por hacerlo, debía llevarlo a cabo los martes y los sábados en una tabla separada que se ponía a su disposición en la calle Mayor.

El monopolio era absoluto --como solía serlo en todas partes-; nadie, fuera del obligado, podía vender carne de carnero, vaca o toro, por mayor ni por menor, en tianguis (los lugares donde se hacían contrataciones públicas de géneros), asesorías ni paraje alguno. Pero la realidad indígena imponía dos excepciones: una, la de los indios llamados nacateras, que vendían a ojo y sin peso en la plaza, y a quienes sólo se exigía que comprasen las reses al abastecedor, en pie o por cuartos. La otra excepción estaba en las fiestas de los pueblos en que solía matarse alguna res, que no tenía que ser, necesariamente, del obligado.

Sí aportaría, en cambio, los toros que hiciera falta en el caso de que se organizara en la corte alguna corrida, como solía hacerse. Al fin y al cabo, luego vendía él mismo su carne. Él o sus subarrendados. Porque se le permitía subarrendar las tablas dichas, si no quería

\footnotetext{
20 LóPEZ ROSADO [3], 93, cita sólo los seis primeros y el último y añade Tlacomulco, como lugares en los que el obligado se comprometía a surtir de carne, además de México.
}

R. I., 1997, n. ${ }^{\circ} 209$ 
poblarlas por sí. Lo que en todo caso se le prohibía - y desde tiempo inmemorial - era llevar la carne a las casas particulares. Era una forma de evitar preferencias ocultas en favor de uno $u$ otro. Todo el que quisiera carne y hubiera de comprarla tenía que acudir a las tablas. Se exceptuaban los religiosos - sin duda, para no forzarlos a romper la clausura-, a quienes sin embargo se les tenía que llevar públicamente, en canal y a lomos de mula, y no en hombros de indios.

\section{El PAN DE MÉXICO}

Según acabamos de ver, por su propia naturaleza el abasto adjudicado por remate implicaba el monopolio del mismo por parte del obligado. No así el abasto por administración, como era el del maíz, en el cual el cabildo y el pósito sólo tenían una función complementaria, tendente a asegurar que hubiera un mínimo. En este caso, la ciudad se surtía, mayoritariamente, de los particulares, y lo acopiado por los comisionados del cabildo sólo constituía una pequeña parte. En el quinquenio 1763-1767 se vendieron en la alhóndiga mejicana 182.225 fanegas de maíz, de las que 171.851 eran particulares y sólo 10.374 del pósito ${ }^{21}$ : entre el 5 y el 6 por ciento. Años antes, el marqués de Croix había dispuesto que se comprasen cada año hasta 40.000 fanegas, que era lo que cabía en los almacenes que tenía el pósito de la corte en la vecina Toluca ${ }^{22}$. Pero una cosa era el ideal, otra la realidad de lo que se compraba y otra, además, lo que se consumía.

En lo que al precio se refiere, el de los bienes subastados, como la carne, se fijaba en el propio pliego de condiciones. En cuanto al grano, no había tasa fija - a diferencia de lo que sucedía en la España europea hasta 1765 - pero tampoco la libertad de precio que rigió aquí desde esa fecha, sino que, desde el virrey a la Junta del Pósito, cualquier autoridad podía fijarlo si lo creía procedente en cualquier momento. Para evitar que hubiera contradicciones entre ellos bastaba la prudencia y el sentido común. En diciembre de 1760 fue el virrey en persona, marqués de Croix, quien decidió que el trigo se

21 Cfr. AнCM, vol. 3.694 (Pósito y Alhóndiga. 1693 a 1770), exp. 21 (Mandamiento de la Real Audiencia...).

22 Cfr. ibidem, exp. 57 (Auto sobre providencia...). 
vendiera a catorce reales la carga si era bueno o de superior calidad y a 12 y medio si inferior o del desmedrado, y eso hasta la siguiente cosecha $^{23}$, para la que aún faltaba medio año, que era el de los meses mayores. En cambio, en el maíz, fueron los de la Junta del Pósito -0 sea el corregidor y los diputados del mismo y de la alhóndiga - quienes ordenaron que se pusiera en venta al precio que pidieran por el suyo los encomenderos. Esto en 1760. Porque en 1762 ellos mismos - los de la Junta - lo fijarían en un peso y siete reales la fanega ${ }^{24}$.

En esto del dinero había otra diferencia capital entre México y Madrid o, mejor, entre Nueva España y España. Allí los panaderos no eran pobres como la mayoría de los de aquí. Y por lo tanto había menos, aunque el número no fuera despreciable: 58 en 1766, sesenta en 1768, para una ciudad como la de México, que debía rondar, al alza, los cien mil habitantes. Todos los panaderos se distinguían con el tratamiento de don y un par de ellos acababan de permitirse comprar un cargo en las milicias provinciales, que se habían introducido definitivamente en 1766. Concretamente, uno era capitán y otro teniente. Formaban gremio y actuaban de hecho como corporación, con un apoderado y diputados, que elegían de vez en cuando en junta general, por más que ésta se reuniera sin regularidad, cuando las justicias de la ciudad lo creían conveniente, aunque la convocaran a instancias de los propios panaderos ${ }^{25}$.

De forma similar a la de tantos lugares de la España europea, se cocían en México tres tipos de pan: el floreado, el común y el bajo. Se distinguían por la calidad de la harina y desde luego por el precio. Además, para dificultar aún más que hubiera engaños, se exigía de

23 Cfr. АнCM, vol. 3.452 (Panaderías y pulperías), exp. 3 (Bando sobre manifestaciones y remesas de trigos). El decreto es de 7 de diciembre de 1760 . Los de la ciudad lo comunican a las justicias de Chalco, Tetzcuco, Toluca, Tacuba, Cuautitlan y demás de la comarca. Cuando impliquen cambios fonéticos (como en el caso de Tetzcuco, que acabamos de mencionar), respetaremos la grafía de los topónimos tal como aparece en el documento, prescindiendo de su grafía actual.

24 Vid. AHCM, vol. 2.189 (Cuentas del Pósito, 1738 a 1812), exp. $9(1760=$ Autos sobre venta de maízes del Pósito...) y 10 (1762 = Libro de venta de maízes del Pócito...).

25 Cfr. dictamen del procurador general, 14 de junio de 1766, АНСM, vol. 3.452 (Panaderías y pulperías), exp. 4bis (México y maio 9 de $1766=$ Algunos Dueños de Panadería...), y exp. 5 (México y octubre 6 de 1768 años = Junta celebrada por los Tratantes en Panadería...). Se aprobaría nuevo reglamento para el gremio de panaderos el 14 de noviembre de 1770: ibidem, exp. 6 (México y Septiembre de 1772 = Superior Resolución del Exmo. Señor Virrey...). Sobre la población de México en esos días, LóPEz RosADo [3], 56. El mismo autor, 71, dice que en la época virreinal había de 48 a 50 panaderos en México. 
cada panadero que pusiera su marca o pintadera en cada una de las piezas de las dos primeras clases de pan. Que eran las que se vendían con peso y precio fijos; no así el pan bajo, que podía pesar poco o mucho - ocho, diez o más onzas - y cuyo precio fijaban los merchantes regateando con los compradores.

Sobre el papel, el floreado se elaboraba con flor de harina, el común con toda la harina y el pan bajo con la cabezuela, que era la harina gruesa que salía del trigo una vez sacada la flor, o con el llamado granillo. En la práctica, las posibilidades de adulteración eran mil. En el bajo, a la cabezuela o al granillo se le añadían tal cual vez repasos inservibles para el pan común (o sea los restos de la harina pasada por el torno), a veces harinas de Toluca, conocidas por su mala calidad, u otros granillos, a veces salvado.

En cuanto a la forma, del pan floreado y del común se hacían tortas grandes, en tanto que el pan bajo se cocía en tortas pequeñas, tortitas; solían darse doce o catorce tortitas por media del común. Alguno hacía pan bajo en tortas redondas echándole anís por encima.

En general, los panaderos propiamente dichos sólo hacían pan común y algunos pan floreado. El pan bajo solían hacerlo los pambaceros. Pero, ante la carestía de 1750 , un panadero había tenido la ocurrencia de hacer pan bajo en forma de tortas y no de tortitas, dando torta y media por medio. Lo llamó pan del Carmen y se hartó de vender. En los años siguientes, hubo de vez en cuando algún otro que acudió al mismo expediente; pero en 1764, cuando lo hizo don Diego González de Retana, dueño de la panadería de la Cruz del Factor, se le acusó de engaño, se le multó con veinticinco pesos y se prohibió hacerlo de nuevo, por más que él insistiera en que estaba hecho con repasos de harina de la mejor calidad, que era mucho más barato y que, en último término, merecía poco menos que un homenaje por ayudar de este modo al prójimo ${ }^{26}$.

Los de la ciudad y el corregidor de México celaban todo esto como pudieran vigilarlo las justicias de cualquier ciudad de la España europea. Se controlaba la calidad del grano, fuera trigo o maíz, y la del pan y, por controlarse, también se controlaba a los controladores. En 1762, el corregidor pasó a inspeccionar las carnicerías y, aparte de poner varias multas por faltas en el peso, comprobó que no

\footnotetext{
26 Cfr. AнCм, vol. 3.452 (Panaderías y pulperías), exp. 4 (México Año de $1764=$ Causa formada Contra Don Diego Retana...).
} 
estaba presente ninguno de los cuatro fieles repesadores designados por la ciudad, a quienes por lo tanto puso en prisión por unas horas, amonestó y acabó por sustituirlos ${ }^{27}$. Al año siguiente, el alcaide de la alhóndiga sería llamado al orden por no estar todo el tiempo necesario para vigilar el maíz que entraba ${ }^{28}$.

Al vigilar también los precios, no pretendían las justicias de México - como tampoco las de España - evitar desde luego la alteración de los mismos que era normal a lo largo del ciclo agrícola: con su elevación en los que en Castilla se llamaban meses mayores y la baja cuando llegaba la cosecha. La diferencia en este punto estribaba en que el trigo y el maíz se contrapesaban en parte y eso era un elemento importante para equilibrar el mercado: el tiempo de la recolección del primero era el mismo que en la España europea (final de la primavera y entrada del verano), de manera que el precio tendía a elevarse desde esta última estación para culminar en la primavera siguiente, antes de la cosecha; en tanto que la mayor parte del maíz se recogía en el otoño y, por lo tanto, solía bajar en octubre y noviembre y comenzar después la remontada que culminaba en el verano, cuando bajaba el trigo ${ }^{29}$. En algunas comarcas se hacía además

27 Cfr. AHCM, vol. 83A, Actas de Cabildo, f. 15, 23 de marzo de 1762.

28 Cfr. AHCM, vol. 3.694 (Pósito y Alhóndiga. 1693 a 1770), exp. 51 (1763 = Autos del Alcaide de Alhóndiga, y Mayordomo de los maízes del Pócito...). México:

29 Vid. por ejemplo lo sucedido en 1760 y 1762 con el maíz del pósito de la ciudad de

1760:

25 -VII, 18 reales precio en que se mantuvo hasta

6 -VIII, 17, hasta

8 -VIII, 16, hasta

18 -VIII, 17, hasta

22-VIII, 16, hasta

26-VIII, 2 pesos, hasta

28-VIII, 16 reales, hasta

22-IX, 2 pesos, hasta

25-IX, en que cesa el registro

1762:

$22-\mathrm{XI}, 10$ reales, precio en que se mantuvo hasta

27-XI, 7, hasta

12-I-1763, en que cesa el registro

Cfr. AнCM, vol. 2.189 (Cuentas de Pósito. 1738 a 1812), exp. $9(1760=$ Autos sobre venta de maízes del Pósito...) y exp. 10 (1762 = Libro de venta de maízes del Pócito...). Falta el registro de 1761 y buena parte de 1762 .

R. I., 1997, n. 209 
una primera cosecha de maíz en la primavera y, en algunas, especialmente buenas y húmedas, tres a lo largo del año y eso contribuía aún más al equilibrio. Cuando era caro lo uno, era barato lo otro ${ }^{30}$.

Lo cual no significa que no hubiera escasez, primero porque los consumidores de pan de trigo y de pan de maíz no eran los mismos; los primeros eran los españoles (europeos o criollos) y sus asimilados; los segundos, los indios y, según Clavijero, hasta los mestizos, o sea los más pobres, que no tenían medios para adquirir el pan de trigo aunque faltara el de maíz.

Aparte, el peligro principal para que la cosecha se perdiera - la seca- podía afectar en un mismo año a las dos especies a que nos referimos, como ocurrió en 1761-1762 y en la tremenda crisis de $1785-1786$.

Había escasez, además, porque —como en la península - había especulación. Cuando los precios apuntaban al alza o se veía venir una mala cosecha, ocurría lo mismo en ambas partes: cosecheros y compradores procuraban almacenar el grano y retenerlo hasta que subiera aún más, y eso - la propia retención- hacía que la inflación fuera mayor si se convertía en un comportamiento general. Y, de hecho, la retórica y los razonamientos eran iguales que al otro lado del Atlántico:

Viva la gracia de Dios - leemos en un suelto de Querétaro de 1786-. Los avaros van bajando la ley, pues ya se va apareciendo aquí tanto maíz, que este cabildo rehusa comprar por el precio corriente del día, aun dándoselo fiado, porque creemos que han de bajar, porque las señales son de aguas tempranas, y esta opinión es común; a más de que la felicidad con que por esas tierras [de Valladolid] van los maíces de riego, han hecho eco, con lo que esto anima a los pobres y tiemblan los avarientes, de los que no faltará quien se quede con tres o cuatro mil fanegas de maíz sobrante ${ }^{31}$.

También - hay que decirlo- había casos de altruismo ejemplar por parte de otros propietarios de rentas o de haciendas. Don Juan

\footnotetext{
30 Aunque los movimientos estacionales de precios que expone FloRESCANO, pp. 88111 , son visiblemente semejantes a los de Europa.

31 Apud FlORESCANO, Fuentes para la Historia de la crisis agrícola de 1785-1786, México, 1981, Archivo General de la Nación, I, p. 303. Una reacción semejante al otro extremo del continente americano, en Cochabamba, en LARSON (1990), pp. 290-2.
} 
Garrido, colector de diezmos de Tezcuco, andaba en 1786 de un lado a otro buscando maíz movido de las comunes necesidades que se padecían diariamente en la ciudad, sobre todo los pobres y en especial los indios ${ }^{32}$. Y algo parecido hacían al propio tiempo en la ciudad de México don Juan Coutiño, trajinero en compra de granos, que vendía maíz en la alhóndiga a menor precio que los demás, y en San Juan Teotihuacan don Juan Revelo, que buscaba maíz por doquier para darlo a los pobres a precio de $\operatorname{coste}^{33}$. En el Real del Dulcísimo Nombre de María Tepantitlán, el rico propietario don Juan Antonio Romero, descubridor de aquellas minas, y su hermano y apoderado, don Juan Isidro, daban de comer a los pobres, incluso sirviéndoles personalmente... mientras que el primer diputado don Juan Antonio Valdez compraba el maíz en la plaza a cuatro pesos y lo revendía a seis en su casa ${ }^{34}$.

También en México, y en la época de que hablamos, se abría camino la idea fisiócrata que se imponía en España ya en los años sesenta y que hacía del labrador el hombre productivo por excelencia $^{35}$. «Sin plata - argüía el administrador del conde de Medina y Torres en 1785 - puede vivir el hombre, y acaso más feliz; pero sin las semillas perecerá ciertamente de hambre. No es pues disputable la prerrogativa y preferencia que los labradores deben gozar, respecto aun de los mineros, y la mayor razón con que deben ser excepción de toda regla» ${ }^{36}$. Sólo que en Nueva España iba aún más allá - ya en los años ochenta-y se planteaba como problema de justicia.

Cuando el ciudadano, bajo de sombra y cubierto del aire - escribe el mismo personaje--, se entretiene en una reprobada u honesta diversión, [...] entonces pues los labradores reciben sobre sí las más duras heladas, resisten el más frío y rápido viento, sufren los ardores del sol, del nacimiento al ocaso, pasando de este extremo al de unos espesos aguaceros, cuyas aguas hasta los huesos les penetran, y después de sufrir las inclemencias del día, pasar a resistir sobre un caballo o andando

\footnotetext{
32 Apud FloresCANo [3], I, p. 383.

33 Ibidem, I, 447. En caso de Coutiño, ibidem, I, 421-3. Más casos, ibidem, pp. 58-60.

${ }_{34}$ Cfr. ibidem, I, pp. 535-60.

35 Véase nuestro «La evoluci6n de los conceptos de propiedad y bien común en la España del siglo XVIII», en Haciendo historia: Homenaje al profesor Carlos Seco, Madrid, Universidad Complutense, 1989, pp. 227-234.

36 Apud FloReSCANO [31], I, p. 116. En el mismo sentido, ibidem, p. 315.
} 
a pie la violencia con que les acomete el sueño y el más regalado se tira sobre el suelo, en una humilde choza, o en una infeliz tlapisquera ${ }^{37}$.

Está nuestro corazón - escribe en un edicto el obispo de Valladolid de Michoacán al comenzar 1786 - muy penetrado de aflicción y pena, a vista de las iniquidades clandestinas que en las ventas y compras de maíces, otras semillas y comestibles se han cometido, y continúan cometiendo, poniendo a los pobres en el deplorable estado de no tener qué comer: joh y cuántos discípulos del rico avariento ha dado a luz la actual calamidad! Los pobres Lázaros piden y claman; pero en lugar de darles socorro, $\mathrm{o}$ a lo menos honesta ocupación en que ganen su sustento, muchos y muchos han cerrado sus trojes y paneras para vender sus semillas a medida de su insaciable codicia, pero en nombre de Dios y según el Santo Evangelio les anunciamos para descargo de nuestra conciencia que ciertamente hallarán cerradas las puertas del Cielo, y que oirán de boca del mismo Jesu-Christo esta infalible y terrible sentencia: tuve hambre y no me disteis de comer; id pues, malditos al fuego eterno en donde encontraréis a vuestro jefe y corífeo el rico avariento ${ }^{38}$.

Y el obispo de La Puebla de Los Ángeles en esas mismas circunstancias:

La causa de que se trata es de Dios, del Rey, del bien público y común de los pueblos, y principalmente de los pobres, cuyo socorro y alivio en sus respectivas necesidades nos está expresamente mandado por las sagradas escrituras, Santos Padres, y decisiones de la Iglesia ${ }^{39}$.

No era un caso insólito de adelanto a los tiempos, sino al contrario: continuidad en la aplicación de los criterios de la vieja teología moral escolástica. A despecho de los fisiócratas, continuaba latente el principio de que originariamente la propiedad era común. Lo dice expresamente en 1785 el propio virrey al dar cuenta de sus medidas previsoras y de cómo se hace colaborar a los más ricos en uso de la obligación de sostener la patria y de los derechos que hacen revivir la primitiva comunión de bienes ${ }^{40}$. La propiedad privada sólo se había hecho necesaria en virtud del pecado y pesaba sobre ella una fuerte hipoteca social, el bien común, que hacía que, en teoría y en la práctica, los gobernantes dispusieran de los bienes privados cuando lo

\footnotetext{
37 Ibidem, I, p. 116.

38 Ibidem, I, 289. Otros ejemplos, ibidem, I, pp. 57, 243, 389-90.

39 Ibidem, II, p. 520.

40 Ibidem, II, p. 640.
} 
consideraban preciso, como ocurrió en aquellos años con notable frecuencia. Contra lo que veíamos en la España europea ${ }^{41}$, en la novohispana Querétaro y 1785 llegó a abrirse expediente contra varios ricos propietarios que se mostraron renuentes, según el corregidor, a contribuir con un préstamo para adquirir los alimentos imprescindibles $^{42}$. En España, por el contrario, ya en los años sesenta del siglo XVIII, se iba imponiendo el concepto fisiócrata, protoliberal, de propiedad. En México no.

\section{LA ENFERMEDAD, LA DIETA Y EL HAMBRE}

Como en España, cundía en Nueva España la beneficencia, sobre todo eclesiástica, que se acentuaba en los días de crisis. El planteamiento era el mismo a los dos lados del Atlántico. Pero la medida no. Si respecto al resto de Europa, el sistema benéfico español y las actitudes de ese mismo tenor estaban más desarrollados ${ }^{43}$, no era así en cuanto a México. Ante la crisis, los eclesiásticos con mayores rentas no se limitaban a prestar dinero y especies con generosidad, como hacían en España, sino que, de una parte, era más frecuente que lo hicieran gratuitamente, como limosna estricta ${ }^{44}, y$, segundo, a lo que ya existía como institución permanente añadían verdaderos sistemas extraordinarios de previsión. Ante la hambruna enorme de 1785-1786 el obispo de Valladolid no sólo franqueó sin intereses largas sumas de pesos, sino que envió edictos a sus curas para que hicieran cuanto pudieran y, entre otras cosas, asegurasen siembras suficientes para la siguiente cosecha. Algunos hicieron verdaderas exploraciones territoriales para dar respuesta adecuada a esta orden. El de La Puebla de los Ángeles, lo mismo. El arzobispo de México llegó a decirse dispuesto a que se vendieran todas las joyas de la iglesia, incluidas las propias, además de exhortar por medio de los

41 En el lugar citado: «La evolución de los conceptos de propiedad y bien común...», pp. 227-34.

42 Vid. FloRESCANO [31], I, pp. 328-51

43 Como afirma, por ejemplo, Óscar DI SIMPLICIO, Le rivolte contadire in Europa: I prandi movimenti che scuotono le compagne nell'época Moderna. Roma, Editori Riuniti, 1986, p. 117.

${ }_{44}$ Casos concretos de limosna sin interés, apud FloresCANo [31], I, pp. 59, 139, 141, $180,221,224,236-7,241,430-1, y$ II, pp. 526-7, 613, 640, 745.

R. I., 1997, n. 209 
púlpitos, de los confesores y de su propia pluma a que se evitara la usura, más en una situación como aquélla.

[...] tenemos ya acordado —escribía en 1786-, que si fuese necesario para vuestro socorro y sustento se vendan la crujía de plata, lámparas, y todas las demás alhajas y vasos sagrados de nuestra Santa Iglesia Catedral. Prelado y cabildo estamos muy penetrados de que nunca seremos más felices, ni más honrados que cuando por daros de comer nos hallemos en el glorioso caso de celebrar el Santo Sacrificio de la Misa en cálices de vidrio, pues de esta suerte (como sucedió en los primeros siglos de la Iglesia) los obispos, canónigos y sacerdotes tendríamos el glorioso timbre de ser de oro ${ }^{45}$.

¿Era esto reflejo de una mayor virtud? Al menos lo era de adecuación a la realidad. El mercado de México estaba mucho menos monetizado que el español; la moneda corriente era muy escasa y, de hecho, en las ordenanzas de 1750 sobre las pulperías -tiendas en las que se vendía todo lo necesario para el abasto- se obligaba a los pulperos a admitir como moneda el cacao ${ }^{46}$. En un sistema tal, los préstamos en dinero y con intereses tenían poco sentido; no se podían devolver en economías cuyas ganancias dinerarias se reducían, en las épocas de bonanza, a una reducida cantidad de dinero que servía para vivir al día y pagar el pequeño tributo que se exigía a los indios, si de indígenas se trataba. Una de las respuestas más frecuentes a la crisis enorme de $1785-1786$ por parte de las autoridades municipales civiles y eclesiásticas fue, de hecho, pedir la exención fiscal para sus gentes. Al elevarse el precio del maíz, no les llegaba para todo - comer y tributar- ni aun a aquellos que tenían trabajo. Que ése era otro problema. Porque muchos no lo tenían y, de éstos, sólo a algunos quedaba alguna cosa para venderla o empeñarla a cambio de comida, como solían hacer y de hecho hicieron en semejantes circunstancias ${ }^{47}$.

Por otra parte, la propia agricultura estaba menos desarrollada, no en el sentido de que se desconocieran las técnicas mejores, sino en

45 Cfr. ibidem, II, pp. 645-6. Otros casos de clérigos, entre los muchos que se documentan ibidem, en I, pp. 54-7, 59-60, 87, 140, 242, 251, 264, 304, 424, y II, pp. 525-6.

46 Cfr. LóPEz RoSADo [3], 91. Más sobre la escasez de moneda, ibidem, pp. 106-7.

47 Ejemplos de ganancias y necesidades dinerarias de indios, en FLORESCANO [31], II, pp. $713,718,730-2,735-8,743$. 
el de que no se habían apurado, como en la península ibérica, las posibilidades agrícolas del territorio. Aún abundaban los terrenos vírgenes que eran propicios para el cultivo o que podían serlo con una labor previa de drenaje o de riego; de modo que cabía plantearse como un remedio la búsqueda de tierras aptas para la siembra y la cosecha. Así ocurrió de hecho en 1785-1786 en no pocos lugares.

Es singular que esta disponibilidad de suelo en Nueva España conviviese con una realidad que empezaba a alejarse de España y que era la relación entre crisis de abastecimiento y mortandad. De facto, la crisis de 1761-1762 tuvo esta ligazón ${ }^{48}$ y mucho más la de 1785-1786. Pero no era una relación siempre sencilla. Concretamente, no siempre se trataba de hambre que llevara a la muerte por inanición, sino de endemias que, al asociarse a una mala alimentación, aumentaban su capacidad de hacer daño. La diferencia es importante, entre otras cosas porque era más difícil ponerle remedio.

La dieta de los pobres era extraordinariamente frugal. En gran parte de Nueva España se reducía a maíz, sobre todo comido como atole (unas gachas de maíz cocido y molido) o en forma de tortas; también frijoles y garbanzos, habas y chile, más alguna otra semilla de consumo menos frecuente, como los camotes (o sea la batata), la yuca (y su enorme raíz, de que se hace la tapioca) o el huacamote, además de las papas. En un informe de la época se añadía que en cambio, en Manila, la dieta mínima estaba compuesta de arroz y frijoles; en La Habana y Campeche, de yuca, huacamote o pan de garbanzos, alimento al que se acudía asimismo en La Puebla de los Ângeles y alguna rara vez en la ciudad de México por extraordinario apetito ${ }^{49}$.

Otro recurso, cuando escaseaba el maíz, era aprovecharlo mejor, mezclando el grano con el olote o corazón de la mazorca, que no se

48 FLORESCANO [31], 186, resalta la importancia de las epidemias de 1761-64 y 17689, que figuran entre las principales del siglo XVIII.

49 Apud Florescano [31], II, p. 580. Cfr. ibidem, II, pp. 529, 580, 620. Еn АнСм, vol. 751A (Juntas de Ciudad), f. 102v, 13 de marzo de 1762, se lee que los alimentos de los indios novohispanos se reducen a frijoles, garbanzos, habas e iguales semillas, pimientos (que llamamos chile) y tortillas, se entiende de maíz. Más elementos de comparación con otros ámbitos hispanos, en la literatura bromatológica. Concretament vid. Víctor $M$. PAtiÑo R., Historia de la cultura material en la América Equinoccial. Tomo 1. La alimentación en Colombia y en los países vecinos. Bogotá, 1984. Eduardo EsTRELLA, El pan de América. Etnohistoria de los alimentos aborígenes en El Ecuador. Madrid, CSIC, 1980. Del atole, ved la descripción de Clavijero en GUERRERO (1987), p. 103. 
solía comer. Y otro más, moler avena para el $\operatorname{pan}^{50}$. También se acudía al maguey, que era el cultivo indígena novohispano que seguía al maíz en importancia; era muy común; se empleaba habitualmente para fabricar sogas y elaborar el pulque, pero sus cabezas y raíces servían de alimento en los momentos más difíciles ${ }^{51}$, a veces asando en barbacoa sus jiotes ${ }^{52}$, en ocasiones raspando el tallo y haciendo tortas con las raspaduras, mezcladas por ejemplo con salvado $^{53}$, y chupando el aguamiel que destilaba por la zona raspada (suasada, se decía ${ }^{54}$ ).

Se comía pescado, claro está, entre los pueblos pescadores, en la costa y los ríos. Pero, donde no eran tales, como sucedía en La Puebla de los Ángeles, el pescado sólo resultaba accesible a las gentes acomodadas $^{55}$. Y ya vemos que la carne, de cuyo abasto hemos hablado, estaba ausente de la dieta de los menesterosos. Lo cual no obstaba para que los días de necesidad lo fueran también para aquéllas - las más acomodadas-, y los obispos por lo tanto tuvieran que acudir en esos casos a relevar de la obligación de la abstinencia cuando llegaba la cuaresma ${ }^{56}$.

La oferta del mercado era desde luego más amplia; el alcalde mayor de Guadalajara veía en 1786 , con contento y esperanzado, muchas huertas de sandías, pepinos, melones, calabazas, habas, chiles, jitomates y otros productos que iban a resolver muchas cuitas ${ }^{57}$. Y, por los mismos días, el corregidor del Real de Bolaños, también en Nueva España, hablaba de la presencia en el mercado de varias de esas cosas y, ademas, lentejas, manteca, jamón, huevos, gallinas, pollos y piloncillo o panochita de dulce ${ }^{58}$. Pero el problema era su precio $^{59}$, que ni siquiera en tiempos de bonanza los hacía asequibles a la multitud de individuos que vivían al margen del intercambio

\footnotetext{
50 Cfr. FloresCano (1981), II, p. 642. Lo mismo del olote, con detalles de la cocción, ibidem, I, p. 304.

51 Cfr. ibidem, II, p. 642. Sobre la importancia relativa del cultivo del maguey, LóPEZ ROSADO [3], p. 66.

52 Cfr. ibidem, I, p. 342.

53 VId. ibidem, I, p. 468.

54 Vid. ibidem, I, pp. 468-9: suasar.

55 En este sentido, ibidem,II, p. 529.

56 Vid. ibidem, I, pp. 285 ss. entre otros lugares.

57 Cfr. ibidem, I, pp. 96-7.

58 Cfr. ibidem, I, p. 98. La aclaración sobre el piloncillo, ibidem, 1, p. 224.

59 Vid. ibidem y p. 286.
} 
propiamente mercantil. Los indios mismos solían cultivar, es cierto, frijoles, chías - con que hacían una bebida refrescante-, chiles, calabazas, tomates y algunas hortalizas de origen español, igual que cuidaban gallinas y otros animales domésticos ${ }^{60}$. Pero el elenco puede engañarnos con la idea de que todos tenían de todo. No era realmente así.

La sobriedad de los más pobres les permitía, paradójicamente, defenderse con mayor facilidad de las crisis. Necesitaban poco, muy poco, para sobrevivir. En 1786, en varias casas de gente acomodada de Guanajuato, se mantuvo a los pobres con arroz, tortillas, pan de semita y carne ${ }^{61}$, y el cura de Santa Elena del Real de Nieves, del obispado de Durango, consiguió alimentar a más de trescientos a base de caldo, carne y tortilla al mediodía y atole abundante por la noche, «en cuya operación -reconocía- se advierten día por día algunas gentes desmayadas» ${ }^{62}$.

Además, la vegetación silvestre les ofrecía más posibilidades de sustitución que las que la meseta semidesértica de la España interior ponía a disposición de sus habitantes. En estas circuntancias se acudía también a las bellotas, allí donde había encinares ${ }^{63}$; al nopal, que existía por doquier, tanto a su fruto - la tuna - como a la carne de sus pencas... Y un eclesiástico comisionado del obispo de Valladolid de Michoacán propuso que se consumieran granos de parotas, que se acercaban al sabor de la avellana o de la almendra, solas o mezclada con maíz en tortillas. La vaina que contenía tales granos solía emplearse como jabón, para lavar, y como quitamanchas, y el tronco del árbol parota, para construir canoas ${ }^{64}$. Pero en momentos de necesidad valía todo lo que no matara. Incluso al tlazole - o sea la planta del maíz, sin la mazorca—, que se empleaba y se usa habitualmente

\footnotetext{
60 Vid LóPEZ RosAdo [3], pp. 67-9.

61 Cfr. FloResCANo [31], I, 224. El pan de cemita (sin duda, de la acemita española) se componía de diversos ingredientes, según el país. En el Diccionario de la lengua española de la Academia (21 ${ }^{\mathrm{a}}$ ed.) se atribuye la expresión a Argentina y 110 a México, en tanto que cemila se registra en El Salvador y Nicaragua y es pan de salvado con relleno de dulce hecho con algún fruto.

62 Apud FloRESCANO [31], I, p. 67. p. 708.

63 Como en San Pedro Paracho, cerca de Valladolid de Michoacán: vid. ibidem, II,

${ }^{64}$ Cfr. ibidem, I, p. 308. Más sobre la parota, ibidem, p. 310.
}

R. I., 1997, n. $^{\circ} 209$ 
como forraje para el ganado, hubo quien llegó a recurrir en el pueblo de Apango, provincia de Avalos, Nueva España, en $1786^{65}$.

Le consta al que declara - dice un testigo de Japalpa, en la misma provincia y ocasión- que fue tanta la escasez de víveres en aquel pueblo que la fruta de zapotes, aún sin estar en aquella debida, se la comieron, y a su conclusión se pasaron a otro lugar a la fruta de pitayos y acabándola se desparramaron en solicitud de raíces, por los cerros, haciendo en ellos tantas huellas que parece haber andado por ellos manadas de cerdos; [...] Hubo un individuo en dicho pueblo que de una comida de moras que dio por su necesidad otro día amaneció muerto ${ }^{66}$.

En Santa Elena del Real de Nieves citado, dejaron los nopales de los montes en su mero tronco, después de haber saciado el hambre con su carne ${ }^{67}$.

En el valle de San Francisco, obispado de Michoacán, y sin necesidad de que la cosecha de maíz fuera mala, la gente solía comer - sobre todo en los meses mayores- nopal, maguey, flores y dátiles de palma, biznaga revuelta con maíz en tortillas, mezquite (una suerte de algarrobilla) convertido en pan, y garambullo (una especie de cactus $)^{68}$.

Pues bien, con este panorama, en 1761-1762, en México, no hubo hambruna en sentido estricto y sin embargo se multiplicaron las muertes por las epidemias. Que esto venía con la escasez era cosa sabida: lo previeron los munícipes mejicanos en la primavera de 1761 , al constatar la falta de lluvias ${ }^{69}$. Y en efecto: en el otoño había ya viruelas, que estaban produciendo una gran mortandad, tanta que el cementerio de la catedral, donde enterraban a los muertos, no tardaría mucho en quedar pequeño. Hubo que habilitar un camposanto más, junto a San Lázaro. Y un hospital para los enfermos en una sala del Señor San Juan de Dios porque los que había en la ciudad no daban abasto para los miserables indios y demás pobres (españoles $o$ de color quebrado), indistintamente, que se veían afectados por el

\footnotetext{
65 Vid. ibidem, II, p. 685.

66 Ibidem, II, p. 683.

67 Vid. ibidem, I, p. 67.

68 Vid. ibidem, I, p. 342.

69 Vid. АнCM, vol. 82A, Actas de Cabildos, f. 57v, 17 de junio de 1761.
} 
mal $^{70}$. Eran sobre todo habitantes de los barrios de Candelaria, Santo Tomás, San Pablo y San Antonio Abad y de los pueblos inmediatos, como Jamaica y Ixtacalco ${ }^{71}$. No había duda: fallecían - dice un regidor en noviembre de 1761 - por la necesidad en que se hallan ${ }^{72}$.

Pero en marzo se había sumado la epidemia temible de matlazahualt y, en abril, seguía muriendo gente y los enfermos no cabían en el hospital que se había habilitado por cuenta del pósito; hubo que pensar en ampliarlo a la casa llamada de Velázquez o de la Teja. El del convento de Nuestra Señora de Bethlem estaba a rebosar... Además, hacía falta que en el Hospital Real de Indios se abriera una sala para los convalecientes; porque a los enfermos los daban de alta a los tres o cuatro días de haberse liberado de la fiebre, que es cuando se creía que exhalaban los vapores que podían producir el contagio. En junio, la epidemia de matlazahualt salía ya de la ciudad, extendiéndose... ${ }^{73}$. Oscilarían nada menos que entre 14.000 y 23.000 las personas fallecidas por viruelas o matlazahualt en $1761-1762^{74}$.

70 En AHCM, vol. 83A, Actas de Cabildos, f. 14, 12 de marzo de 1762, dice exactamente que el hospital es para «los miserables indios y demás pobres españoles o de color». Modifico arriba la puntuación de la manera que considero más acorde con lo que se quería decir. Era una frase hecha. Se repite ibidem, vol. 751A (Juntas de Ciudad), f. 102v (13 de marzo de 1762), añadiendo lo de quebrado indistintamente.

Los demás datos precedentes, ibidem, vol. 82A, Actas de Cabildos, f. 74 (3 de noviembre de 1761), 75 (4 de diciembre), 75v (15 de diciembre), y vol. 751A (Juntas de Ciudad), f. 95-6 (24 de noviembre), 96-96v (9 de diciembre: de todos los hospitales van muchos al del convento bethlemítico con motivo de la epidemia), 114 (7 de diciembre de 1762).

Dice que se debe abrir hospital como se hizo para la anterior epidemia de matlazahualt. Debe ser la de 1737: vid. ibidem, vol. 3.674 (Policía...), exp. 1 (Secretaría del Exmo. Ayuntamiento de México año de 1743 = Certificación del Contador de esta N.C. sobre lo gastado en el Hospital de N.S. de Guadalupe (alias) la Teja en la epidemia de matlazahua), 2 folios. De paso, se identifica la casa de la Teja que mencionamos arriba, más adelante. Sobre lo habitual de este recurso, ibidem, exp. 2 (Epidemia $=$ Año de $1722=$ Testimonio del decreto del virrey sobre que se forme en el parage más a propósito un hospital...), 2 ff.

Sendas visiones globales sobre los hospitales mejicanos de la época, en Josefina MURIEL, Hospitales de la Nueva España, tomo 2; Fundaciones de los siglos XVI y XVIII, México, Editorial Jus, 1960; Fidel AGUIRRE MEdRANO, Historia de los hospitales coloniales de Hispanoamérica, Nueva York, Arenas, 1992; Francisco GUERRA (1994), El hospital en Hispanoamérica y Filipinas 1492-1898, Madrid, Ministerio de Sanidad, 1994.

71 Cfr. ibidem, vol. 83A, Actas de Cabildos, f. 14, 12 de marzo de 1762.

72 AнCM, vol. 82A, Actas de Cabildos, f. 74, 3 de noviembre de 1761.

73 Cfr. AHCM, vol. 751A (Juntas de Ciudad), f. 101v (6 de marzo de 1762), 102v (13 de marzo), 103v ( 24 de abril), 107 (3 de junio), y vol. 83A, Actas de Cabildos, f. 16 (2 de abril), 17v (23 de abril). Dice matlezagua y matlazagua. En otro lugar citado supra matlazahua. La forma matlazahualt, ibidem, vol. 3.674 (Policía...), exp. 5 (N. Ciudad $1787=$

R. I., 1997, n. $^{\circ} 209$ 
En 1785-1786 sí hubo hambre en cambio, pero además enfermedades, algunas de las cuales habían comenzado a extenderse años atrás, no procedían por tanto de la hambruna pero hallaron en ella el aliado idóneo. En la ciudad de México, lo que se declaró en noviembre de 1785 fue una fiebre catarral epidémica benigna, que afectó a la mayoría de los habitantes pero que se curaba fácilmente. Y, sin embargo, fueron muchos los muertos.

La causa había que buscarla por tanto en la debilidad y en la salubridad y no sólo en la producción de alimentos, como se desprendía de los informes recabados por los gobernantes del virreinato, a quienes no pasaba desapercibida la estrecha relación entre hambre, epidemia y mortalidad. Las epidemias hacían el mayor estrago en la gente pobre - por lo común desordenada, dirían los de la Audiencia en 1786-; desordenada a veces por vicio y en ocasiones por miseria $y$, con frecuencia, por desidia o ignorancia: muchos no iban al hospital y no pocas veces preferían los remedios que les aconsejaba un curandero. Quienes en 1784, por ejemplo, los habían inducido a tomar aguardiente cuando les comenzaba a doler el costado y, en 1785, a que bebieran pulque con naranja... No bastaban los médicos y boticas si, además, no se acudía a ellos.

Por otra parte no había médicos - continuaban los del Real Acuerdo - sino en La Puebla de los Ángeles, Guadalajara, Valladolid, Oaxaca, Durango, Guanajuato, San Luis Potosí, San Miguel el Grande, Querétaro, Veracruz, Orizaba y Jalapa. En lo demás del reino, había a lo sumo una botica y, en los más, el curandero de turno.

Quaderno $2^{\circ}=$ Formado sobre providencias para precaver la enfermedad), f. 7. MURIEL (1960), 248, dice que «en 1762-63 en todo el país se sufre una intensa epidemia de viruelas llamada impropiamente matlazahualt». En la documentación que citamos, en cambio, las dos aparecen diferenciadas, aunque no con entera claridad. La misma autora, ibidem, 247, aporta los síntomas del matlazahualt, hablando del de 1735: «escalofrío, dolor de cabeza y estómago, alta temperatura y hemorragia nasal, se supone que se trató de una epidemia de tifo.» Isabel OLMOS SÁNCHEZ, «Reformas higiénico-sanitarias en el México ilustrado, 1786-1821». Cuadernos de Investigación Histórica, n. ${ }^{\circ} 14$, pp. 25-44, 30, afirma que era «una especie de mezcla de peste y tifus que atacaba a las clases sociales más pobres por consumir alimentos en mal estado.». José Luis Lorenzo me comunica que, por su parte, en el Diccionario Porrúa: historia, biografia y geografia de México, 2. ${ }^{a}$ ed., México, Porrúa, 1965, en la correspondiente voz, se lee que la identificación más correcta del matlazahualt es la de tifo exantemático y que los españoles la identificaron con el tabardillo, dentro de cuya definición entraba sin embargo otras fiebres eruptivas.

74 Según los cómputos que recoge LóPEZ ROSADO [3], p. 125. 
Y luego estaba el problema de la limpieza, sobre el que se insistía asimismo, sin éxito, desde hacía años. Una Junta de Policía se preocupaba de estos asuntos; las calles principales se regaban de hecho por la mañana con el agua que corría por los caños; se exigía a los asentistas que dejaran las calles y plazas limpias; las recorrían además carretones donde se depositaba la basura. Cuando había epidemia, en torno a los hospitales a los que se acogían los enfermos se ponían luminarias de leña de ocote, que era muy resinosa, después de las oraciones. Pero, en las casas de vecindad, las inmundicias se echaban a la calle y, el día que no había agua en los caños, quedaban allí. La ropa vieja se vendía en el baratillo o se empeñaba en las pulperías sin que se supiera quién la había llevado, si sano, enfermo o muerto. En los lavaderos se mezclaban las prendas, fueran de quienes fuesen. Los petates de paja que habían sido lecho de enfermos o moribundos se dejaban en la calle cuando ya no servían y a veces eran pasto de las vacas que vagaban por la ciudad, cuya leche se vendía. Los animales muertos quedaban en las calles... ${ }^{75}$.

\section{LA RESPUESTA A LA CRISIS: REZOS, MENDIGOS Y MOTINES}

La participación abrumadora de los eclesiásticos en la resolución de los problemas del abastecimiento novohispano se correspondía rigurosamente con un factor distinto, pero íntimamente relacionado, que era la omnipresencia del recurso a la religión, otra vez en medida mucho mayor de lo que podía verse en España. Ante la mera amenaza de escasez, en junio de 1761, el procurador general de la ciudad de México había propuesto que se hiciera un novenario a la la Virgen de los Remedios, trasladando la imagen, como era la costumbre, del santuario a la catedral ${ }^{76}, \mathrm{y}$, desde entonces, todo el penoso ciclo vegetal que siguió y el de las epidemias se preñaron de recursos parejos. Otro novenario, en este caso a Nuestra Señora de

75 Cfr. dictamen de la Audiencia, 19 de mayo de 1786, АнCM, vol. 3.674 (Policía...), exp. 4 (Junio de $1787=$ Año de $1786=$ Expediente formado sobre la curación de la presente epidemia...). Salvo la existencia de la Junta de Policía (que constatamos entre otros lugares ibidem, 82A, Actas de Cabildos, f. 75, 4 de diciembre de 1761), la de los carretones de las basuras (ibidem) y el detalle de las luminarias en torno al hospital, que está ibidem, vol. 83A, Actas de Cabildos, f. 14v (12 de marzo de 1762).

${ }_{76}$ Cfr. AHCM, vol. 82A, Actas de Cabildos, f. 57v, 17 de junio de 1761.

R. I., $1997, \mathrm{n}^{\circ} 209$ 
La Piedad, ordenaría el corregidor cinco meses después cuando se convenciera de que había viruelas ${ }^{77}$. Que, como continuaban en diciembre, se intentaría atajar con un tercer novenario y el traslado a la propia catedral del crucifijo de Santa Teresa, que allí se conservaba ${ }^{78}$.

En marzo de 1762 la Virgen de los Remedios vuelve a la catedral ante el matlazahualt ${ }^{79}$. y, en abril, como la epidemia persiste, se hace deprecación a San Roque y otros santos, por cuenta de la Ciudad, en tanto que el arzobispo dispone que haya un novenario más al Señor Sacramentado en la catedral y conventos, con misa, letanía, preces y rogativa ${ }^{80}$.

El caso es que la iniciativa partía no pocas veces de la autoridad superior, o sea el corregidor, que era el navarro Pedro Fermín de Mendinueta, siendo así que en su tierra - en la Pamplona de Navarra, al otro lado del océano- harían frente, sí, al mal tiempo de 1765-1766 con rogativas a la Señora del Sagrario ${ }^{81}$. Pero nada más. ¿Reaparecía en este hecho la diversidad étnica - la población indígena y sus hábitos- que constituía el principal contraste de la sociedad novohispana en relación con la española?

Lo demás era igual o parecido, si bien surgía por doquier este mismo elemento diferenciador. Como en España y en el resto de Europa, la falta de producción agrícola repercutía en el mercado y por lo tanto en las más diversas industrias; dejaba de correr el poco dinero que corría; no pocos artesanos tenían que mendigar; de los pueblos pequeños donde no había posibilidad de abastecimiento sustitutorio - sopa boba de los conventos o limosnas de propietarios generosos de rentas abundantes - la gente abandonaba sus casas para buscar el pan en otro lugar y, con todo esto, los caminos se poblaban de vagabundos y las ciudades de mendigos. Se expresaba, en otras palabras, la misma cultura de la migración que cundía por Europa con extraña unanimidad. «En el día - escribía el virrey en abril de 1786 - se ve mendigar en las calles, paseos, plazas, zaguanes y aun en los templos una multitud de pobres de ambos sexos, no pocos

77 Cfr. ibidem, f. 74, 3 de noviembre de 1761.

78 Cfr. ibidem, f. 75v, 15 de diciembre de 1761.

79 Cfr. AнCM, vol. 751A (Juntas de Ciudad), f. 101v, 6 de marzo de 1762.

80 Cfr. AHCM, vol. 83A, Actas de Cabildos, f. 17v, 23 de abril de 1762, y vol. 751A (Juntas de Ciudad), f. 103v, 24 de abril.

81 Vid. AMP, Consultas, núm. 42, f. 244-54v, 13 y 27 de enero de 1766. 
desnudos y cargados de hijos, que mueven a lástima y compasión» ${ }^{82}$; los que salían de los pueblos más alejados de los núcleos urbanos, «agotado en breve su corto aliento, se encontraban en los caminos y en las paradas agonizantes, como esqueletos animados, y no pocos muertos a los pies de los árboles. ¡Ojalá todo esto tuviera algo de exageración [...]!», exclamaban los de la Real Audiencia adivinando acaso el pensamiento del lector. » Ofrecían las indias - añaden - vender el fruto de sus entrañas, a sus hijos pequeños, por dos o tres reales» ${ }^{83}$; «han empeñado a sus hijos por temporadas de uno o dos años», ratifica un comerciante de Atzcapusalco ${ }^{84}$.

Y era la misma que en Europa la reacción de los gobernantes: acudir a las obras públicas - como continuar con el empedrado y terminar la catedral, en la ciudad de México - aparte de habilitar, si no lo había, un hospicio adonde se obligara a acudir a todo mendigo, a fin de distinguir entre los verdaderos pobres y los holgazanes que aprovechaban la ocasión para vivir a costa del prójimo ${ }^{85}$.

Otra manera reiterada de responder a la necesidad, que hallamos asimismo en España y que cundía por Europa, era la de entrabar el grano para impedir que se extrajera rumbo a otros parajes. En 17851786 se repitió con profusión, si bien es cierto que es que el propio virrey había dispuesto que, mientras no se encontrara abastecido el respectivo lugar, no se dejara salir, si no era para la corte novohispana, y esto porque era aquí adonde acudía más gente ${ }^{86}$. No eran tiempos —en México- de libertad de comercio. La que se había promulgado en España en 1765 no se había entendido para Indias y, aquí, la gente estaba dividida al respecto, igual que en la península europea ${ }^{87}$.

Tal vez por eso mismo, las trabas a la libre circulación de los granos solían ponerlas los propios gobernantes, apenas los súbditos.

82 Apud FloresCano [31], II, p. 609. Más testimonios de esta migración, ibidem, I, pp. $80,105,133,153,212,214,223-5,232,324,326,337,428,431,436,468,476,500$, y II, pp. 529, 576, 605-12, 618, 643, 650, 677, 682, 685, 709, 711-4, 737-8. Lo mismo, al otro extremo del continente americano, en Brooke LARSON, «Rural rhythms of class conflict in Eighteenth Century» en JOHNSON y TANDETER [3], pp. 292-3.

83 Ibidem, II, p. 618.

84 Ibidem, I, p. 732.

85 Un ejemplo de esta reacción, ibidem, II, pp. 605-6.

86 Casos de trabamiento de este tipo, ibidem, I, pp. 52, 72, 99, 105-7, 110, 115, 125, 128 , $143,145,152,163,177,212,359,384,418,421-2,456,492$, y II, pp. 507, 562, 574, 634.

87 Vid. por ejemplo ibidem, I, pp. 215-6. 
Quienes, cuando lo hacían, daban a tal intervención la forma de protesta $\mathrm{y}$, por lo tanto, llegaba a ser a veces - cierto que pocas veces, muy pocas en los días a que nos referimos - conato de motín. El alcalde mayor de Tezcuco decía en julio de 1786 que era tanta la escasez de maíces, que había gente que acechaba en los caminos a los viandantes que los acarreaban de uno a otro lugar y, al descubrirlos, se los arrebataba en tanta multitud, particularmente mujeres y muchachos con demasiado susurro ${ }^{88}$.

En agosto de 1786, en San Andrés Chalchicomula, hubo quien revendió a ocho pesos el maíz que había comprado a cinco y la vaguedad de voces en el Común se hizo temible; temeroso de una sublevación, el teniente de aquel partido forzó a bajar los precios. Pero se añadía a ello la saca de maíces con otro destino y eran continuos los clamores por esa razón -informaba el teniente ${ }^{89}$.

El 26 de septiembre, un gran tropel de gente de la plebe, de ambos sexos, se presentó en las casas del justicia mayor de Pachuca, por su parte, diciendo a voz en grito que perecían por la falta de maíz y que en la colecturía de esta ciudad no les querían vender por ningún precio del mundo el que había acopiado en las trojes. Ante lo cual había optado el justicia por obligar al colector a que se lo vendiera al precio corriente, recelando que el Común de dicho vecindario formase un alboroto que causara alguna desgracia contra el referido administrador ${ }^{90}$.

Alboroto que sí se había dado en Zacatlán en julio y que se repitió en octubre, por parte de los indios y las indias de aquella cabecera ${ }^{91}$.

La dinámica, en fin, era la misma. La diferencia estaba en la existencia de una población numerosa - mucho más que en España- que vivía prácticamente al margen de las transacciones mercantiles y de la economía monetaria, en niveles frugales. Eso y la fuerte intervención, que hemos visto, de los eclesiásticos configuraban ciertamente un panorama semejante y diverso a una vez entre ambos lados del Atlántico.

\footnotetext{
88 Ibidem, I, p. 384.

89 Ibidem, II, p. 517.

90 Ibidem, I, p. 400.

91 Vid. ibidem, II, 569. La noticia de junio, en MEDINA (1983), p. 252.
} 
In 1761-1786 there was a lot of food-riots in Spain and a few ones in the New Spain. Why? The author studies the Mexican supplying system in an economical, social and anthropological perspective and compares it with the Spanish one. That shows some differences: no-public indigenous supplying, communistic doctrines about propriety, importance of charity and a less developed protest culture.

R. I., $1997, \mathrm{n}^{\circ} 209$ 